\title{
The COVID problem reflected by economics - A bibliometric analysis
}

\author{
ANDREA MAGDA NAGY ${ }^{1 *}$ (D), BOGLÁRKA KONKA ${ }^{2}$ (1) and \\ ÁDÁM TÖRÖK ${ }^{2,3}$
}

${ }^{1}$ Department of Economics, University of Pannonia, Egyetem u. 10, H-8200, Veszprém, Hungary

${ }^{2}$ Department of International Economics, University of Pannonia, Veszprém, Hungary

${ }^{3}$ Department of Economics, Budapest University of Technology and Economics, Budapest, Hungary

Received: July 2, 2021 - Revised manuscript received: July 23, 2021 - Accepted: August 15, 2021

() 2021 The Author(s)

\begin{abstract}
COVID-19 has been the "hottest" topic in many fields of research during 2020-2021. Our analysis focuses on the publications related to the pandemic in the business and economics area. Using the Web of Science database, the main international research patterns in this field have been analysed. Our research covers less than two years (2020 and part of 2021), but the number of publications is large (more than 1,000) in this limited time span. The publication patterns of the CEE countries have also been examined. Bibliometric and social network analysis was used to assess which countries and institutions published the most during this period. For analysing the main trends in the given field, keyword analysis was performed.
\end{abstract}

\section{KEYWORDS}

COVID-19, literature review, bibliometric analysis, business and economics

JEL CLASSIFICATION INDICES

F01, I23, M00, D85, 039

\footnotetext{
*Corresponding author. E-mail: nagy.andrea@gtk.uni-pannon.hu
} 


\section{INTRODUCTION}

The COVID-19 pandemic erupted in December 2019. The impacts of the virus have reached, besides the healthcare system, the economies, societies, enterprises and governments of all countries of the world. The scholarly world was obliged to swiftly react to the crisis. Publication activity has spectacularly increased within and outside life sciences. Economics is one of this.

We used bibliometric analysis to assess the main trends of COVID-related research in business and economics between January 1, 2020 and March 26, 2021. Our study has three parts. We offer a survey of pre-2019 scientometrics literature in Section 1, focussing on publications with relevance to the COVID problem. Our database, research questions, and methodology are presented in Section 2. Section 3 provides a bibliometric analysis of the COVID-related publications in Business and Economics (B\&E) with special attention to the performance of Central and Eastern European (CEE) countries.

\section{LITERATURE REVIEW}

The emergence of the SARS-Cov-2 virus causing COVID was almost immediately followed by a fast increase in the number of related publications (e.g., Haghani et al. 2020; Kagan et al. 2020; Palayew et al. 2020; Torres-Salinas 2020; Cai et al. 2021) in databases (e. g. PubMed; Web of Science or Scopus). As detailed by Haghani - Bliemer (2020): more than 12 thousand related articles were identified by Scopus in the first 5 months after the eruption of the pandemic, and 30 thousand after 7 months. This trend came as no surprise if considering former publication activity related to viruses and infectious diseases such as H1N1, Ebola, SARS, or Zika (Zhang et al. 2020a). In the titles of studies listed by the database PubMed, COVID was the most frequently used abbreviation in 2020 (Barnett - Doubleday 2021). This mushrooming of COVID-related publications was also due to the fact that the usually time-consuming processes of reviewing and editing had to be drastically shortened due to the importance of the topic (Zhang et al. 2020a; Palayew et al. 2020).

There was also a flip side to this dynamic increase of publications activity. There proved to be a multiplication of errors in studies which had to be corrected after publishing. For example, the survey of PubMed by Yeo-Teh - Tang (2020) demonstrated that the retraction rate of COVIDrelated publications increased from 0.081 to $0.097 \%$ in just one month, between May 3 and June 8, 2020. As opposed to this, the same indicator for Ebola, H1N1, HIV or MERS related research remained below $0.025 \%$, with the one for cancer related research not reaching $0.04 \%$.

These striking differences have adequate explanations. In the first place, the COVID epidemic is not an issue of the past as most viruses mentioned are. Data collection problems may distort sampling (Yeo-Teh - Tang 2020), while mutations of the virus may reduce the relevance of former clinical results. da Silva et al. (2021) came to similar conclusions. Based on data collected on June 30,2020 , they revealed that $0.8 \%$ (101 documents) of relevant publications in Web of Science, and $0.5 \%$ (114 papers) in Scopus were corrected within a short lapse of time.

The increased frequency of errors in COVID-related research made it plain that knowledge sharing is essential for successful treatment of the pandemic. This is also why the open access publications have gained ground (Lee - Haupt 2021). Belli et al. (2020) calculated that 59.2\% of coronavirus related publications were open access between 2001 and 2020. If, however, only the 
year 2020 was considered, the same share went up to $91.4 \%$. This was due to the publishers' commitment to accelerate COVID-related research. da Silva et al. (2021) came to similar conclusions for the first half of the year 2020: both in Web of Science and Scopus, the percentage share of open access articles within COVID-related papers was above 80.

Most of these publications were produced by the USA and China in 2020 (Hossain 2020; Zyoud - Al-Jabi 2020; Lee - Haupt 2021; Su et al. 2021). The U.S. comes as no surprise in this regard, whilst China's prominence might be related to its leading role in identifying the virus. Between January 1 and April 23, 2020, 39.0\% of the publications surveyed came from China, with about $30 \%$ of them produced in international co-operation (Fry et al. 2020). The UK and Italy were also highly active in this field of research (Zyoud - Al-Jabi 2020; Lee - Haupt 2021; $\mathrm{Su}$ et al. 2021). These latter cases seem to be supportive of the conclusion that countries more affected by the virus published more on the topic and were more open to international cooperation in this respect (Lee - Haupt 2021).

Low- and middle-income countries of Africa and South Asia were less active in COVIDrelated research, first of all in the early stage of the pandemic (Fry et al. 2020; Hossain 2020; Wang - Tian 2021). The example of Africa is telling regarding the internationalisation of COVID-related research in the least developed countries (LDC). $20 \%$ of such research on the continent was financed by South Africa, and the rest by overseas sponsors, mostly British and American institutions. Regarding the thematic focus, $25 \%$ of the articles related to COVID published between December 1, 2019 and January 3, 2021 dealt with the African policies, 22\% with health implications of the virus, and only $1 \%$ with therapy and vaccine issues (Guleid et al. 2021).

The effectiveness of COVID-related research is supported by its working language being English (Van Dalen 2001). The keywords of such papers produced in English showed a great variety, but certain aspects of the epidemic were missing. On the contrary, the Chinese publications covered such policy-related special issues as the access of doctors from remote regions of China to information, or traditional Chinese healing practices (Fan et al. 2020).

As an overall trend, the average number of members of international research teams had been growing before the year 2020 (Wuchty et al. 2007; Wagner et al. 2015), but COVID-related teams did not follow this trend. The average number of countries represented by the authors of a publication increased along with a smaller average number of authors (Cai et al. 2021). One possible explanation could be the extreme urgency of making research output widely accessible. This could have been facilitated by smaller, more efficiently managed research teams (AvivReuven - Rosenfeld 2020; Fry et al. 2020; Zhang et al. 2021; Cai et al. 2021). Regarding economics, certain COVID-related fields can be singled out: labour market (Fana et al. 2020; Webb et al. 2020; Williams - Oz-Yalaman 2021), productivity (Dingel - Neiman 2020), fiscal policy (Blundell et al. 2020; Di Pietro et al. 2020), or enterprise development (Ahlstrom - Wang 2021; Brown - Cowling 2021).

The first comprehensive bibliometric study on COVID-related economics literature was produced by Mahi et al. (2021). Publications on economics were surveyed in Web of Science since 1974 using three keywords: coronavirus, pandemics and epidemics. This keyword-based analysis speaks of the dominance of the U.S., the UK and China in this field of research, too. The term "United States" stands out in regard of the frequency of keywords, and also with respect to international co-operation. Partner countries of U.S. researchers include Canada, Germany, and China in the first place. On the other hand, the so-called rate of co-operation (number of cooperative projects per the number of publications) is the highest for the UK, based mainly on 
European partnerships (Italy, Germany and Belgium). The most frequently used economics related keywords included economic growth, income, demand and consumption (Mahi et al. 2021). With other words, the pattern of the eminent keywords in this case is similar to the standard analyses on economic policy.

\section{DATA AND METHODOLOGY}

Our bibliometric research was based on the Web of Science (WoS) database, a widely appreciated repository of high quality scholarly articles and other publications (Ellegaard - Wallin 2015). Our time horizon included publications issued between January 1, 2020 and March 26, 2021. A follow-up data retrieval was performed on June 11, 2021.

Our keywords-based analysis was made more difficult by the fact that the virus and the disease are referred to in several ways in the literature. Our searching algorithm was defined based on the keywords used by Wang-Tian (2021): TS = (covid) OR TS = (SARS-COV-2) OR $\mathrm{TS}=(2019-\mathrm{nCOV})$ OR TS $=$ (coronavirus 2019) OR TS = (coronavirus disease 2019). Each study selected belonged to the category of B\&E within the WoS Social Science Citation Index (SSCI).

The articles downloaded on March 26, 2021 were filtered in the following way. The term "COVID" had to appear in the title, the keywords and/or the abstract of the study. Nine articles did not match these criteria, these underwent individual monitoring. On a final account, 1 article was discarded, which left us with a database of 1,671 articles. It has to be stressed at this point that the conclusions of our study have limited validity only since they are based on a pool of articles produced within a bounded time span.

Four research questions were formulated in order to identify the main characteristics of the pandemic-related economic analyses. Question 1 was about the development of the number of relevant publications within our time span. Question 2 concerned the pattern of fields of research. Question 3 targeted those countries and institutions which excelled in the COVIDrelated economics research. Question 4 has a predictive character: the assessment of possible trends in economics research related to the pandemic. This analysis was performed using keywords, with special emphasis on topics becoming more popular owing to the pandemic both in the global sense and in the CEE region.

Our main analytical tool was the software VOSviewer (VoS) widely applied in scientometrics (e. g., Song et al. 2021; Jeong - Koo 2016), also with respect to the coronavirus (e. g., Nawaz et al. 2020; Yu et al. 2020). This software facilitates the visualisation of relationships between publications, countries or journals using, for instance, citations or names of co-authors. It also has a text mining function that helps demonstrate the network of keywords (Hamidah 2020; Hudha et al. 2020).

\section{ANALYSIS}

\section{Bibliometric analysis of all business and economics publications}

As a starting point of our analysis, the time, language and type (article, book chapter, etc.) structure of publications in B\&E, including the networks of co-authors were examined. The 
number of all publications in the fields covered by SSCI was compared between the years 2019 and 2021 (two entire years and five months, data downloaded on June 11, 2021).

According to Else (2020), more than 100,000 studies related to COVID were published worldwide. Not only life and natural sciences produced impressive numbers. Fig. 1 makes this more than clear for social sciences as well. The first five months of the year 2021 produced $79.7 \%$ of SSCI publications of the entire year 2020. A similar percentage share was even higher for B\&E (91.87\%). Between our two downloads (March 26 and June 11, 2021), the number of B\&E publications increased by $60 \%$.

The seasonal structure of B\&E publications was also analysed. The majority of articles were published after the summer of 2020 and a steady growth in their number is expected in 2021. When comparing the number of B\&E publications for the first five months of the years 2020 and 2021, the difference is substantial: 13 publications in 2020 January-May, while 444 in 2021 January-May. The months with the highest number of publications (more than a hundred) in our database were the months with the highest number of COVID cases in the world.

The language structure of publications shows an absolute dominance of English (99.04\%). The relative shares of Spanish, Portuguese and French are 0.72, 0.12 and 0.06 per cent in order. The language of one single article could not be identified from WoS. The dominance of English does not come as a surprise since this is the language of most scholarly journals in natural and life sciences and quantitative social sciences in the first place. 12 publications in Spanish showed a high degree of institutional as well as geographical concentration. 8 articles could be attached to Mexican institutions (Fondo Cultura Economica: 7, National Autonomous University of Mexico: 1), and 4 to the University of Huelva in Spain. These data provide additional, although indirect evidence on the dominance of English as they show that most journals in the Hispanic world also use this language.

The structure of our database according to the types of publication has been also analysed. $65.71 \%$ of the documents surveyed were articles. According to the WoS, the group "article" consists not only of journal articles but conference papers, case studies, brief communications and technical notes as well. The second largest group (articles, early access) contains articles already existing as an electronic publication (there are not yet assigned to a final issue). The other 11 groups combined (editorial material, meeting abstracts, review, editorial material early

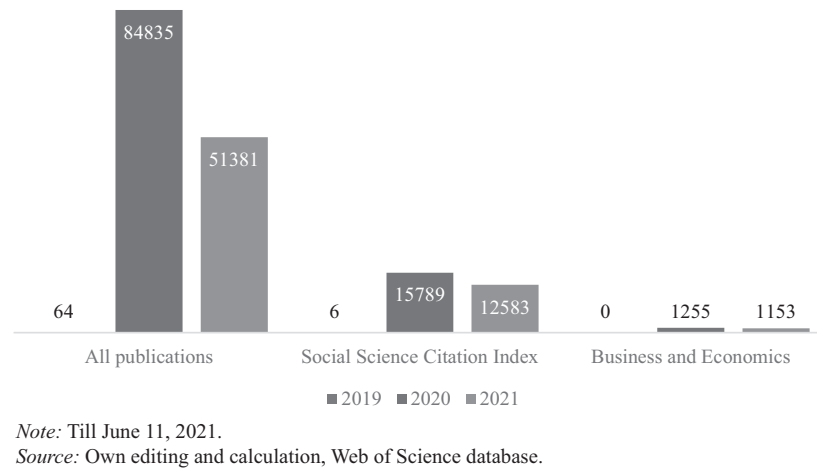

Fig. 1. All, SSCI and B\&E publications worldwide, 2019, 2020 and 2021 
access, letter, proceedings paper, book chapter, book review and correction early access) make out only $15 \%$ of the total sample. There were 8 corrections ${ }^{1}$. This gives $0.48 \%$ of all elements analysed. It is a somewhat lower value than $0.8 \%$ found by da Silva et al. (2021) for relevant publications in all research areas in the WoS.

Our database contained 4,527 names of authors (names, but not necessarily authors), with 404 author names $(8.92 \%)$ connected to more publications than one. This is not surprising since the time span of our analysis is very limited whilst several months are needed for processing an article. The network of co-authorship ${ }^{2}$ speaks of a relatively low level of co-operation intensity (low edge density) between authors. The largest set of co-operations involves 47 authors. The primary reasons for this might be the very recent appearance of this field of research and its as yet limited time horizon. COVID surfaced less than two years ago, and the creation of lasting research co-operations is time-consuming. It seems likely that most co-authorship networks we have identified had existed before COVID appeared, and most authors were supported by their research teams already in place. On average, one article was produced by 3.028 authors. The highest number of authors (46) appeared in an article in World Development (IF: 3.869), in October 2020. This study explores the connection between COVID and the global development paradigm with a closer look at global value chains, digitalisation, debt and climate change (Oldekop et al. 2020). Single author articles made out $19.69 \%$ of our database.

No surprise that citation numbers are not too high within this limited lapse of time. Three articles generated more than 100 citations each. Ivanov (2020, 154 citations) carried out simulations to demonstrate the impacts of the pandemic on global supply chains. Zhang et al. (2020b, with 121 citations) analysed financial markets during the pandemic. Mo et al. (2020, with 102 citations) used a questionnaire to identify factors of workplace stress among healthcare staff in Guangxi. From all publications, $89.4 \%$ received less than 70 citations, while $48.9 \%$ of the publications earned at least one citation until our data retrieval. This means a quite smooth trend of citations, which has an interesting implication for our research. Namely, social sciences and also economics show a very unbalanced citational pattern. A few articles get hundreds of citations while most others are left with a few or even zero each (see e.g., Ruiz-Castillo et al. 2018). The surprising citational pattern of our sample might be, at least in part, due to the shortness of the time span. With other words, some articles within our sample may be expected to get many more citations. COVID being a "hot topic" might also serve as a partial explanation - the initial interest in most articles of the sample might subsist for a few of them only.

Publications are assigned to different Web of Science categories (WoS-C). Most elements in our sample belonged to the categories "Economics", "Management", "Business" and "Business, finance". A significant number of publications were assigned to "Women's studies". "Agricultural economics and policy", "Environmental studies" and "Business ethics" were also represented. Health related areas such as "Health policy and services" were also present. Most if not all fields of B\&E appear in our database in spite of its very limited duration.

\footnotetext{
${ }^{1}$ Correction: A second citation of a publication with the purpose of correcting an error (WoS).

${ }^{2}$ The patterns of co-authorship can be examined knowing a couple of technical details of the VoS software. It uses data from WoS, which may cause certain problems if the names of authors, institutions or keywords are identical. For example, if the same researcher uses slightly different names in different publications, he/she may be treated as several authors by the software. This problem can be corrected manually, but only in the case of smaller data sets.
} 
Special attention was given to WoS-Cs dominant in both 2020 and 2021, and to any possible shift of focus between them. 885 publications were analysed for the year 2020. These belonged to 37 WoS categories. We created a frequency based list of them, with Ranking Position 1 belonging to the most and 36 to the least frequently occurring category (the same ranking position was assigned to categories with equal frequencies). Our sub-sample for the year 2021 contained 786 publications with 39 categories represented. In 2020, there were fewer categories with higher frequencies, while in 2021 more categories with lower frequencies were the major trend. With other words, the publications surveyed from the year 2020 had a somewhat more homogenous thematic character, whilst 2021 brought a more varied thematic pattern of fields of research represented in our sample. Fig. 2 compares the two ranking lists, for the complete year 2020 as well as 2021 until the data retrieval. Both ranking lists contain the TOP 20 (most frequently occurring) WoS categories for the given year. The first three categories remained unchanged, but there were significant shifts in the lower ranks. "Agricultural economics and policy", for example, improved its position from 26th to 4th. "Communication" and "Mathematics, interdisciplinary applications" also showed a significant improvement. To our surprise, "Health policy \& services" and "Healthcare sciences \& services" moved down from the top of the list to below position 20. We suppose this unexpected shift reflects the effort of researchers to discuss COVID-related problems increasingly in non-health fields of science where the impacts of the pandemic also call for solutions. The third health related WoS-C, "Nursing" achieved some improvement. One WoS-C (Food science \& technology) did not figure on the list in 2020 at all, but came into TOP20 next year. Our analysis of WoS categories demonstrates a somewhat changing focus of the COVID-related B\&E research by the year 2021. A wider range of topics appeared in publications from this latter year.

The number of countries indicated in the affiliations of the authors of the publications listed varied between 1 and 25. Altogether, 105 countries appeared in our sample in this way, knowing that WoS treats England, Scotland, Wales and Northern Ireland as separate countries. Fig. 3 lists countries with at least 5 publications (59 countries). The size of the nodes reflects the frequency of the appearance of a country in the sample. The thickness of the edges shows the combined occurrence of nodes.

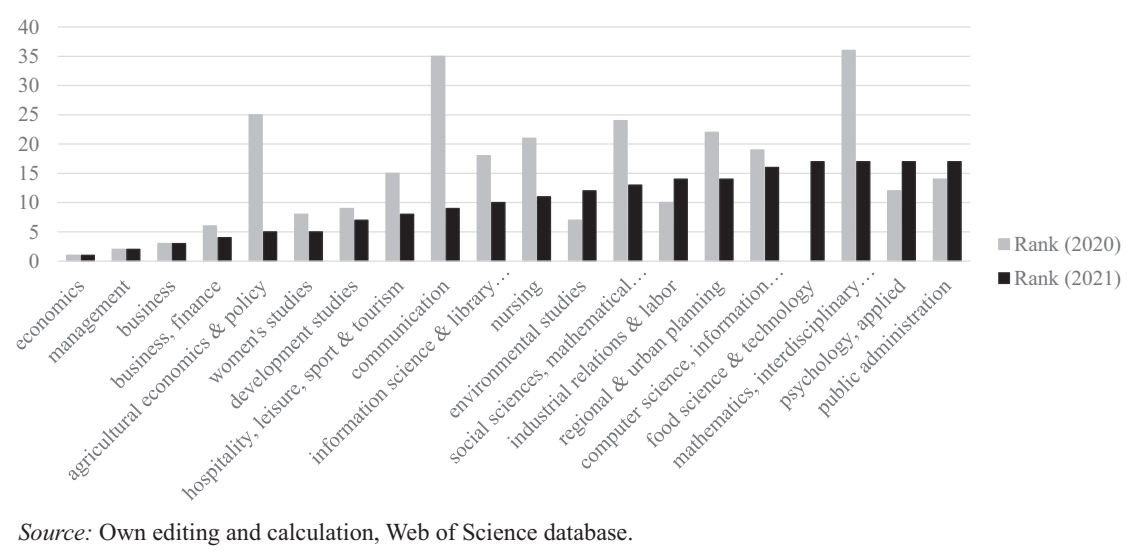

Fig. 2. TOP20 Web of Science Categories (WoS-C) rankings for the time period analysed 


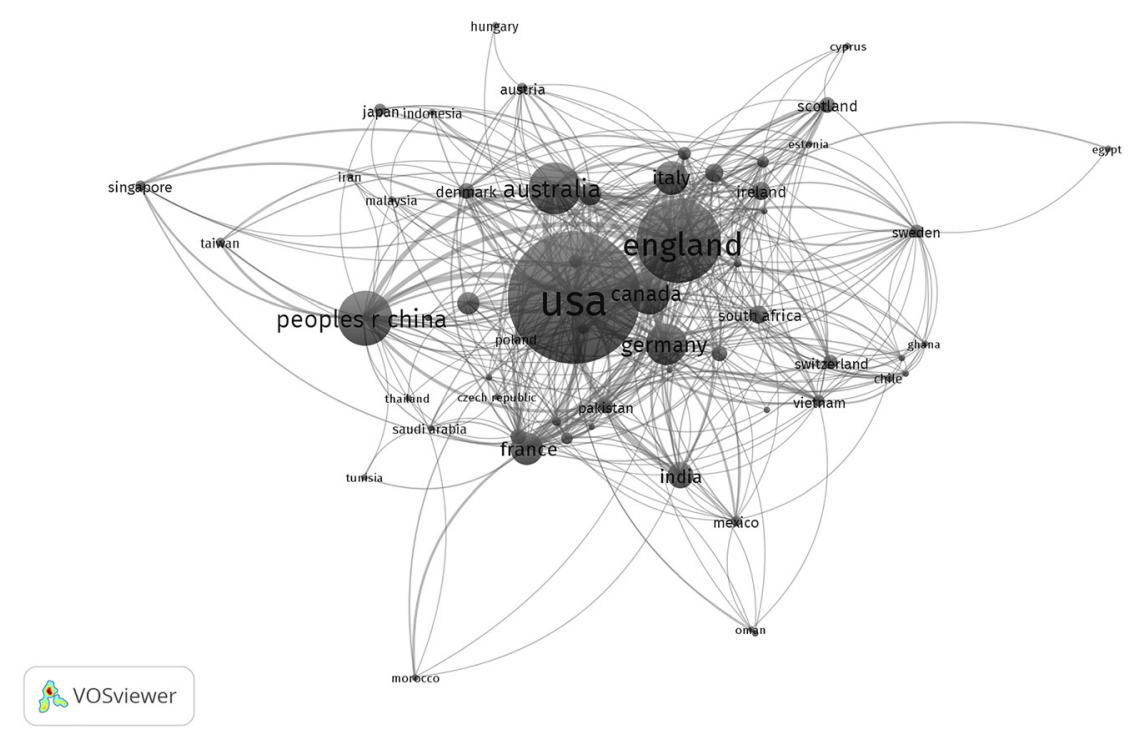

Source: Own editing, Web of Science database, VOSviewer software.

Fig. 3. Distribution of countries with at least 5 publications in the topic analysed

In line with the above, English-speaking countries, the USA - 589, England - 314 (the UK 359), Australia - 156, Canada - 118 are dominant. The European countries with the highest numbers include Germany (115), Italy (89) and France (81). Chinese researchers account for $10.23 \%$ (171) of the total publications in B\&E. These are in line with the findings of Fry et al. (2020), although, in our database, the dominance of the USA is even more pronounced (35\%), while China's performance is also significant, but to a lesser extent than in the previous analysis. Besides China, all other BRICS countries are also represented with publication numbers higher than 25, except for Russia (which instead has a surprisingly high number of connections - 18). The five best performers in Africa include South Africa (39), Kenya (7), Egypt, Tunisia and Ghana (5 each). From the CEE region, the top is Poland (15) then Romania (10), Hungary and the Czech Republic (8 each).

The lower network density (Fig. 3) indicates a lower number of inter-country publication cooperations. England (50), the USA (47), France (37) and Germany (35) have the highest number of country connections, while China comes only the sixth. In the CEE region the country network density is also quite low. The regional leader in this regard is Poland (24), while all other countries in the region have less than 10 publication partners. The Hungarian authors in the sample had co-authorhips only with Western countries (Austria, USA).

Our next focus was the publication output of institutions. Altogether, 1831 institutions were referred to in the affiliations. Most of them could not boast of a considerable production. $87.3 \%$ $(1,598 / 1,831)$ of the sample had less than 10 and 183 had no connections at all within the sample. Expectedly, most publications can be linked to the English or American institutions. The highest number of connections has the University of Oxford (36), the University of Melbourne (25) and NBER (21). Higher education institutions (universities, colleges and business schools) 


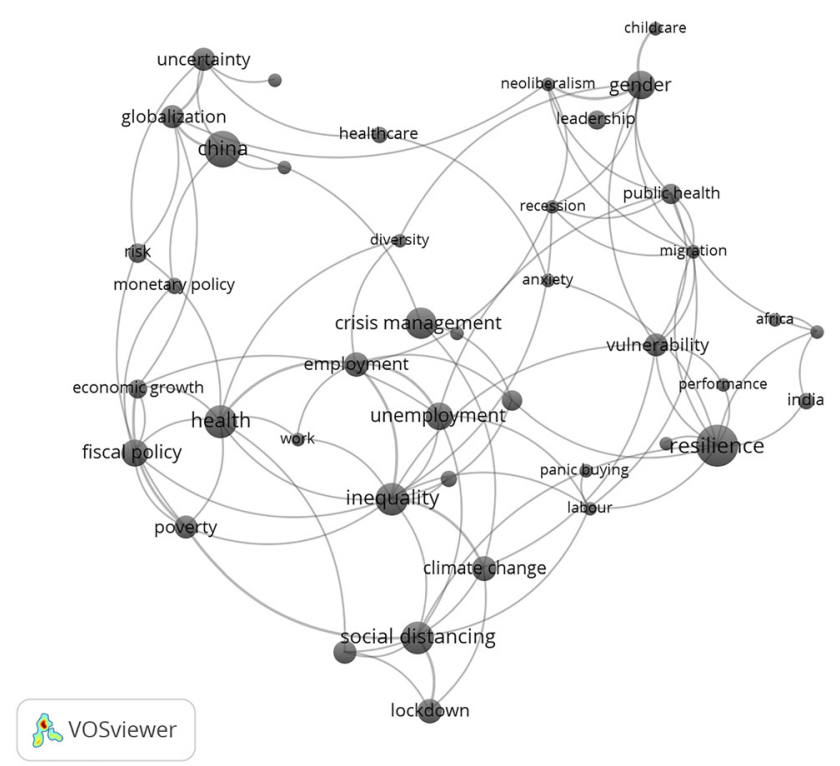

Source: Own editing, Web of Science database, VOSviewer software

Fig. 4. Keyword analysis of publications from 2020 (frequency of 5 or more)

have a combined share of $75.2 \%$ from the total number of institutions mentioned. Research centers, international organisations and banks taking into account together figure with $18.8 \%$ on the list. The part of firms combined is only 5.4\% (Appendix) ${ }^{3} .110$ organisations/institutions (6.0\%) of the list were linked to healthcare as, for example, medical schools or pharma firms.

Publications produced by authors from a single country were mostly authored by researchers from the same institution. With other words, the co-authorship networks were quite weak within the sample in any possible dimension (authors, institutions and countries). This was partly due to the limited time horizon of our sample. It remains, however, open to which extent this low propensity of co-operation was specific to the COVID problem or not.

The analysis of keywords is helpful in understanding the topics structure of COVID-related $\mathrm{B} \& \mathrm{E}$ research. To begin with, 327 articles lacked keywords specified by authors, but 72 out of these had keywords assigned by WoS. The 255 items without keywords had to be omitted from our further analysis. This left us with a pool of 1,416 publications with keywords. The same two time intervals were used again: 2020 and 2021 (until the first data retrieval). The number of publications was 683 and 733, respectively.

Fig. 4 visualises keywords appearing at least 5 times in our database in the year 2020. An important caveat: keywords referring to the epidemic and the virus (COVID-19, COVID-19 pandemic, coronavirus, sars-cov-2, COVID-19 crisis, crisis, pandemics and covid) were

\footnotetext{
${ }^{3}$ A technical problem is worth mentioning at this point. VoS, of course, does not use AI. Therefore, it is unable to handle typos or, similarly, identify the same institution if its name is written in two or three different ways. This is also the reason why certain institutions could not be identified at all (see the "n.a." rows by the Appendix).
} 
disregarded since these constituted the basis of selecting and downloading our own database. This left us with 42 keywords including general terms such as, for example, health, public health or healthcare.

This is a surprisingly wide variety of keywords. Geographical units such as China, Africa and India are represented which speaks of a strong interest in regional analyses of COVID. Macroeconomics showed up with quite great frequency, too (monetary policy, fiscal policy, globalization, economic growth, neoliberalism and recession). There has been a strong researcher interest in the labour market implications of the epidemics (unemployment, employment, labour and work). Social problems were also frequently addressed (inequality, uncertainty, vulnerability, anxiety, wellbeing, food security, gender and childcare). Finance and business related topics (financial crisis, stock market, entrepreneurship and leadership) appeared as well. "Climate change" and "panic buying" also enjoyed some popularity.

A similar analysis of keywords from 2021 is shown on Fig. 5. In this case, we ended up with 62 words (without the keywords referring to the epidemic and the virus).

South Africa could be added to the list of most frequent geographical keywords as compared to the year 2020. Technology related keywords (e. g. artificial intelligence, bitcoin, machine learning, innovation and Google trends) now had a wider representation. Supply chain related issues (e.g. supply chain, food supply chain, and supply chain resilience) have also gained ground, along with the agricultural policy. While only "food security" represented this field in 2020, keywords frequently used in 2021 included "agriculture", "agricultural market and marketing cooperatives", "agribusiness", "food insecurity", "food systems" and "food policy". Family and gender related terms (childcare, gender and feminism) were frequently referred to again. Newly appearing keywords included "knowledge management", "social media", "communication", "e-commerce", "trust" or "tourism". An interesting newcomer was "sustainable".

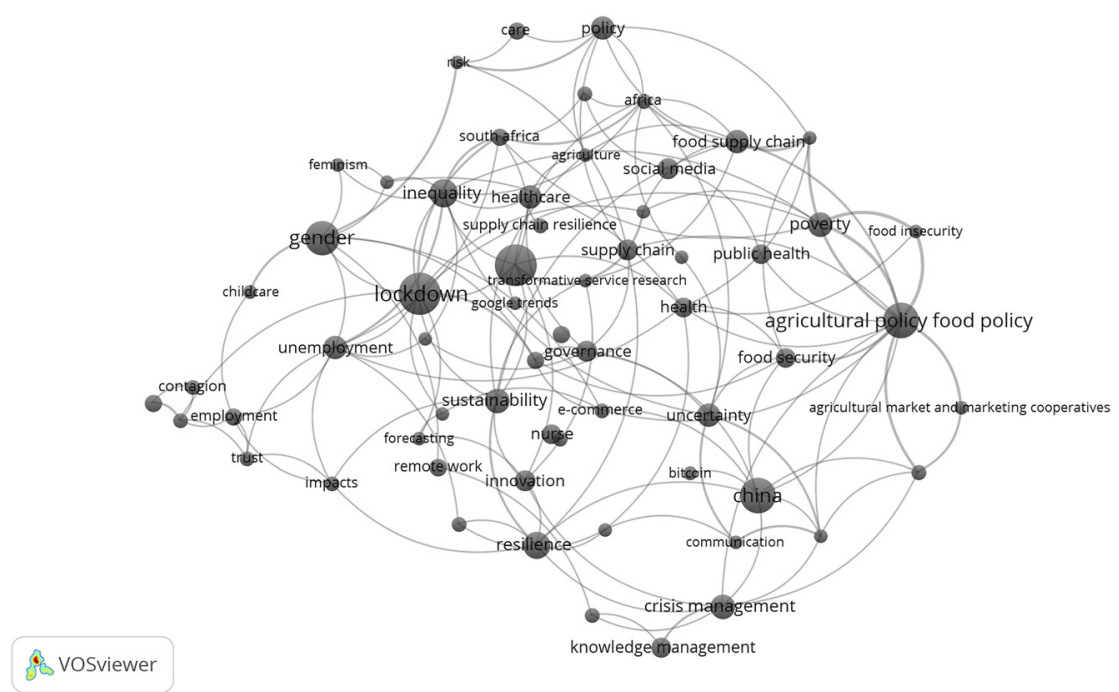

Source: Own editing, Web of Science database, VOSviewer software.

Fig. 5. Keyword analysis of publications from 2021, March 26 (frequency of 5 or more) 
A comparison of the most frequent keywords of the two periods of time speaks of some marked thematic shifts. The focus was rather on more direct implications of the crisis on the key areas of society and the economy in 2020. Next year, however, a much wider range of topics was covered with a closer look at the longer term trends in technology, agriculture or tourism.

\section{Bibliometric analysis of publications from the CEE region}

Our list of countries of the CEE region includes: Hungary, Poland, Romania, Slovakia, Slovenia, Czech Republic, Bulgaria and Croatia. There are altogether 42 publications in our sample (28 from 2020 to 14 from 2021), where the affiliation contains at least one country listed above. Most of them were published as articles or early access articles. There were 6 meeting abstracts, and one editorial material. All of them used English, with one exception: language "unspecified". This turned out to be Romanian.

Out of this pool, $40.5 \%$ obtained at least one citation, and very few of them more than 10 . Only one, Zaremba et al. (2020) was cited 35 times until the first data retrieval. The authors compared the relationship between the severity of the anti-COVID measures and the volatility of financial markets in 67 countries.

First, we looked at the co-authorship patterns between CEE and other countries. Besides 8 CEE countries, other 28 ones appear in the affiliations of our sub-sample. Poland stands out with 15 publications, followed by Romania (10), Hungary and the Czech Republic (8 each) and Croatia (6). The variety of partner countries is wide, LDCs as Pakistan, Brunei and Lebanon appear alongside with Russia, Brazil and China or with the developed countries, such as the USA or France.

We were especially interested in preferences in CEE for publishing with authors from the leading industrial countries. It is well-known that co-authorship with "Western" countries may improve the chances of publishing in highly rated journals. Such evidence was not found by our analysis due to the quite high frequency of partnerships with authors from LDCs. ${ }^{4}$

As shown in Table 1, while Hungary and Romania had no CEE partnerships in this subsample, Slovenia had intra-CEE partnerships only.

Altogether 97 institutions appeared in the affiliations of articles produced in CEE. The connections between these institutions are also very weak. There is one sizeable group of 13 institutions with Jagiellonian University (Poland) at its center. The Bucharest University of Economics Studies has the highest number of cooperation links (4), followed by 3 Hungarian institutions (e.g. University of Pécs, University of Corvinus). The number of institutions from one country was divided by the number of publications from the same country (Table 1). This share oscillated between 75 and 110 with two exceptions. Croatia was represented by six publications and three institutions (50\%). Slovenia's 200\% indicates that there was one publication with two Slovenian authors from two universities. The types of institutions show a pattern similar to our large database with their majority $(80.41 \%)$ coming from higher education (Appendix). The number of healthcare institutions is surprisingly low (5).

\footnotetext{
${ }^{4}$ There were even anecdotal surprises as, for example, the quite close co-operation between Romania and Pakistan or Romania and Brunei. The limited size of our sub-sample does not allow for more generalized conclusions.
} 
Table 1. The distribution of publications

\begin{tabular}{|c|c|c|c|c|c|}
\hline & $\begin{array}{c}\text { All } \\
\text { publications } \\
\text { (A) }\end{array}$ & $\begin{array}{l}\text { Nr. of publication } \\
\text { partners }\end{array}$ & $\begin{array}{l}\text { Partners } \\
\text { from CEE }\end{array}$ & $\begin{array}{l}\text { Nr. of institutions } \\
\text { appearing in } \\
\text { co-operations (B) }\end{array}$ & $\frac{B}{A} \cdot 100$ \\
\hline Bulgaria & 1 & 2 & 1 & 1 & 100 \\
\hline Croatia & 6 & 6 & 2 & 3 & 50 \\
\hline Czech Republic & 8 & 9 & 3 & 8 & 100 \\
\hline Hungary & 8 & 2 & 0 & 7 & 88 \\
\hline Poland & 15 & 24 & 3 & 12 & 80 \\
\hline Romania & 10 & 5 & 0 & 11 & 110 \\
\hline Slovakia & 4 & 3 & 2 & 3 & 75 \\
\hline Slovenia & 1 & 1 & 1 & 2 & 200 \\
\hline
\end{tabular}

Source: Own editing and calculation, Web of Science database.

Our CEE database of publications had 145 authors including authors from the region and co-authors outside of it. There were quite few co-authorships in our sub-sample. 8 publications had one author only, and the highest number of co-authors was 15. On average, the number of authors per publication was 4.29. Nine authors contributed to two or more articles, with seven of them belonging to the community of authors from Pécs ${ }^{5}$. The co-author network visualization shows a small set of nodes with basically no external link to other node sets. This indicates that the publications analysed were written by small groups of authors, but these authors did not really cooperate with other research groups. There are 17 authors whose internal link density is high. All these researchers have a Hungarian affiliation (University of Pécs). Their 4 publications (meeting abstracts) are from the year 2020, in the journal Value in Health about geographical inequalities of COVID in the EU and Hungary (Boncz et al. 2020a; 2020b).

Owing to the small size of the sample, our keywords analysis of the CEE publications looks at the years 2020 and 2021 combined (Fig. 6).

There were 42 publications in our sub-sample. 10 articles had no keywords, but WoS assigned keywords for 2 of these studies. Surveying 34 publications, 152 keywords could be listed. As by the previous keyword analysis, here too, keywords, such as COVID-19, pandemic, coronavirus, novel coronavirus, crisis, coronavirus pandemic, COVID-19 epidemic and COVID-19 outbreak were omitted. The LinLog/modularity clustering method of VOSviewer was used for better visualization purposes only.

Even in this small sub-sample, a wide variety of topics is represented, but most keywords occur only once to three times. By and large, the most frequent keywords here match those in the larger sample. Labor market issues are represented (for example employment, unemployment and automated recruiting), finances and equity markets (e. g. stock market, uncertainty

${ }^{5}$ It is a university town in Hungary. 


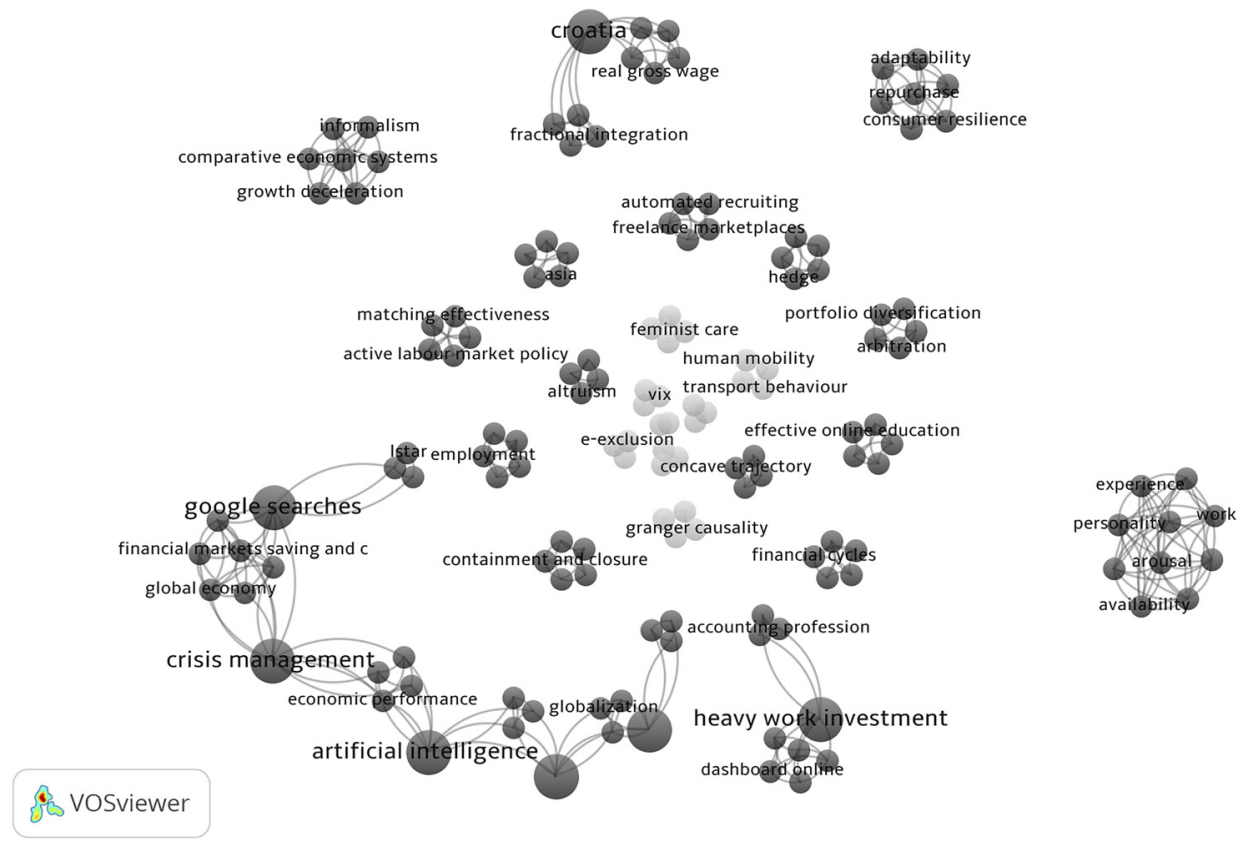

Source: Own editing, Web of Science database, VOSviewer software.

\section{Fig. 6. Keyword analysis of publications from CEE countries}

and volatility) are also referred to. The tech world is not missing either (e. g. artificial intelligence, service robots, digitalisation and biosecurity). Communication (e. g. knowledge and management, Google searches and communication), education (e. g. effective online education and online assessment methods), and consumption (e. g. consumer vulnerability, consumer resilience and adaptability) are also touched upon. Some macroeconomic terms have a regional colour (besides economic growth or economic performance: comparative economic systems and socialist market economy). Family related terms (feminist care and children) also appear. Psychological aspects of the virus (e. g. risk perception, fear and personality) are discussed. With respect to countries, references to China (and The Belt and Road Initiative) stand out. Surprisingly, there are hardly any healthcare related terms among these keywords.

Similarly to our larger database, our CEE sub-sample shows a wide range of topics of interest for researchers. Nearly all fields of B\&E are covered, often using a long term focus in addition to more short term approaches. There seems to be just one kind of deficiency: the economics of healthcare is represented in our CEE database by no more than one single article (Qin et al. 2021).

\section{CONCLUSION}

Since early 2020, COVID has been the "hot topic" in many fields of scientific literature. No wonder a steadily growing number of researchers want to board this increasingly lucrative train. 
In addition to life and natural sciences, social sciences including B\&E also show a mushrooming of COVID-related publications, without any sign of a slowdown. Ever widening researcher interest cannot be doubted. Some scholars might also think they can relatively quickly earn publicational kudos in this field that had not even existed one year and a half before the date of our data retrieval.

Our research took a snapshot of the first 15 months of COVID-related B\&E research. Bibliometrics and social network methods were used to demonstrate the main structural and behavioural trends. There were some surprising findings.

Co-operation between authors is less frequent than expected, but a quite great number of countries is represented. The dominance of the USA and China comes as no surprise, the strong representation of LDCs (e. g. Pakistan, Kenya, or Ghana) is positive. The low intensity of cooperations might be explained by the urgency of coming out with new research output in this fast expanding field. Most researchers could only use their already existing personal networks since they had no time to create new ones. The institutional affiliations speak of the stronger than expected dominance of higher education, with a very weak representation of firms. The CEE countries seem to perform slightly better in this respect.

Our WoS-C and keywords-based analysis pinpointed quite surprising topics seemingly related to COVID, such as women's studies, AI, or the bitcoin. It is also worth mentioning that the publications from 2020 focussed rather on the direct or short-term implications of the epidemic, whilst the studies from the subsequent year revealed a marked shift to the issues of greater strategic interest. Our subsample from the CEE countries shows some bias towards business related topics.

Our research faced constraints irrespective of the shortness of our time span. Only one database was used. Web of Science offers an outstanding global coverage, but some relevant publications may not find their way into it. The dominance of English in WoS might, potentially, be conducive to some important research missing from our larger sample. The size of the larger database prevented manual cleaning of the data (for example, the problem of name ambiguity). The much smaller size of the CEE subsample made manual cleaning possible in that case.

\section{REFERENCES}

Ahlstrom, D. - Wang, L. C. (2021): Temporal Strategies and Firms' Speedy Responses to COVID-19. Journal of Management Studies, 58(2): 592-596.

Aviv-Reuven, S. - Rosenfeld, A. (2020): Publication Patterns Changes due to the COVID-19 Pandemic: A Longitudinal and Short-Term Scientometric Analysis. https://arxiv.org/abs/2010.02594.

Barnett, A. - Doubleday, Z. (2021): Demonstrating the Ascendancy of COVID-19 Research Using Acronyms. Scientometrics, May 16: 1-4.

Belli, S. - Mugnaini, R. - Baltá, J. - Abadal, E. (2020): Coronavirus Mapping in Scientific Publications: When Science Advances Rapidly and Collectively, Is Access to This Knowledge Open to Society? Scientometrics, 124(3): 2661-2685.

Blundell, R. - Costa Dias, M. - Joyce, R. - Xu, X. (2020): COVID-19 and Inequalities. Fiscal Studies, 41(2): 291-319. 
Boncz, I. - Dora, E. - Sebestyen, A. - Kivés, Zs. - Vajda, R. - Molics, B. - Elmer, D. -Betlehem, J. (2020a): Geographical Inequalities of the Incidence of Coronavirus Disease 2019 (COVID-19) Caused by SarsCOV-2 VIRUS in the European Union. Value in Health, 23(2): S562.

Boncz, I. - Sebestyén, A. - Betlehem, J. - Kivés, Zs. - Vajda, R. - Molics, B. - Németh, N. - Dora, E. (2020b): Within Country Regional Inequalities of the Incidence of Coronavirus Disease 2019 (COVID19) Caused by Sars-COV-2 VIRUS in Hungary. Value in Health, 23(2): S558.

Brown, R. - Cowling, M. (2021): The Geographical Impact of the COVID-19 Crisis on Precautionary Savings, Firm Survival and Jobs: Evidence from the United Kingdom's 100 Largest Towns and Cities. International Small Business Journal: Researching Entrepreneurship, 39(4): 319-329.

Cai, X. - Fry, C. V. - Wagner, C. S. (2021): International Collaboration during the COVID-19 Crisis: Autumn 2020 Developments. Scientometrics, 126(4): 3683-3692.

da Silva, J.A.T. - Tsigaris, P. - Erfanmanesh, E. (2021): Publishing Volumes in Major Databases Related to COVID-19. Scientometrics, 126(1): 831-842.

Di Pietro, M. - Marattin, L. - Minetti, R. (2020): Fiscal Policies Amid a Pandemic the Response of Italy to the COVID-19 Crisis. National Tax Journal, 73(3): 619-644.

Dingel, J. I. - Neiman, B. (2020): How Many Jobs can be Done at Home? Journal of Public Economics, 189(September): 1-8.

Ellegaard, O. - Wallin, J. A. (2015): The Bibliometric Analysis of Scholarly Production: How Great Is the Impact? Scientometrics, 105(3): 1809-1831.

Else, H. (2020): How a Torrent of COVID Science Changed Research Publishing - in Seven Charts. Nature, December 16. https://www.nature.com/articles/d41586-020-03564-y.

Fan, J. - Gao, Y. - Zhao, N. - Dai, R. - Zhang, H. - Feng, X. - Shi, G. - Tian, J. - Chen, C. - Hambly, B. D. - Bao, S. (2020): Bibliometric Analysis on COVID-19: A Comparison of Research Between English and Chinese Studies. Frontiers in Public Health, 8(August): 477.

Fana, M. - Pérez, S. T. - Fernández-Macías, E. (2020): Employment Impact of COVID-19 Crisis: From Short Term Effects to Long Terms Prospects. Journal of Industrial and Business Economics, 47(3): 391410.

Fry, C. V. - Cai, X. - Zhang, Y. - Wagner, C. S. (2020): Consolidation in a Crisis: Patterns of International Collaboration in Early COVID-19 Research. Plos One, 15(7): e0236307.

Guleid, F. H. - Oyando, R. - Kabia, E. - Mumbi, A. - Akech, S. - Barasa, E. (2021): A Bibliometric Analysis of COVID-19 Research in Africa. BMJ Global Health, 6(5): e005690.

Haghani, M. - Bliemer, M. C. J. - Goerlandt, F. - Li, J. (2020): The Scientific Literature on Coronaviruses, COVID-19 and its Associated Safety-Related Research Dimensions: A Scientometric Analysis and Scoping Review. Safety Science, 129(September): 104806.

Haghani, M. - Bliemer, M. C. J. (2020): COVID-19 Pandemic and the Unprecedented Mobilisation of Scholarly Efforts Prompted by a Health Crisis: Scientometric Comparisons across SARS, MERS and 2019-nCoV Literature. Scientometrics, 125(3): 2695-2726.

Hamidah, I. - Sriyono, S. - Hudha, M. N. (2020): A Bibliometric Analysis of COVID-19 Research Using VOSviewer. Indonesian Journal of Science and Technology, 5(2): 209-216.

Hossain, M. M. (2020): Current Status of Global Research on Novel Coronavirus Disease (COVID-19): A Bibliometric Analysis and Knowledge Mapping. F1000Research, 9(374): 1-12.

Hudha, M. H. - Hamidah, I. - Permanasari, A. - Abdullah, A. G. - Rachman, I. - Matsumoto, T. (2020): Low Carbon Education: A Review and Bibliometric Analysis. European Journal of Educational Research, 9(1): 319-329. 
Ivanov, D. (2020): Predicting the Impacts of Epidemic Outbreaks on Global Supply Chains: A SimulationBased Analysis on the Coronavirus Outbreak (COVID-19/SARS-CoV-2) Case. Transportation Research Part E: Logistics and Transportation Review, 136(April): 101922.

Jeong, D-H. - Koo, Y. (2016): Analysis of Trend and Convergence for Science and Technology Using the VOSviewer. International Journal of Contents, 12(3): 54-58.

Kagan, D. - Moran-Gilad, J. - Fire, M. (2020): Scientometric Trends for Coronaviruses and Other Emerging Viral Infections. GigaScience, 9(8): 1-17.

Lee, J. J. - Haupt, J. P. (2021): Scientific Globalism During a Global Crisis: Research Collaboration and Open Access Publications on COVID-19. High Education, 81(14): 949-966.

Mahi, M. - Mobin, M. A. - Habib, M. - Akter, S. (2021): A Bibliometric Analysis of Pandemic and Epidemic Studies in Economics: Future Agenda for COVID-19 Research. Social Sciences \& Humanities Open, 4(1): 100165.

Mo, Y. Y. - Deng, L. - Zhang, L. Y. - Lang, Q. Y. - Liao, C. Y. - Wang, N. N. - Qin, M. Q. - Huang, H. Q. (2020): Work Stress among Chinese Nurses to Support Wuhan in Fighting Against COVID-19 Epidemic. Journal of Nursing Management, 28(5): 1002-1009.

Nawaz, K. - Saeed, A. H. - Sajeel, A. T. (2020): COVID-19 and the State of Research from the Perspective of Psychology. International Journal of Business and Psychology, 2(1): 35-44.

Oldekop, J. A. and 46 colleagues (2020): COVID-19 and the Case for Global Development. World Development, 134(October): 105044.

Palayew, A. - Norgaard, O. - Safreed-Harmon, K. - Andersen, T. H. - Rasmussen, L. N. - Lazarus, J. V. (2020): Pandemic Publishing Poses a New COVID-19 Challenge. Nature Human Behaviour, 4(7): 666669.

Qin, X. L. - Godil, D. I. - Khan, M. K. - Sarwat, S. - Alam, S. - Janjua, L. (2021): Investigating the Effects of COVID-19 and Public Health Expenditure on Global Supply Chain Operations: An Empirical Study. Operations Management Research, January.

Ruiz-Castillo, J. - Costas, R. (2018): Individual and Field Citation Distributions in 29 Broad Scientific Fields. Journal of Informetrics, 12(3): 868-892.

Song, Y. - Wu, Y. - Fan, D. (2021): Knowledge Mapping of Three-Dimensional Printing in Biomedical Field Based on VOSviewer. Chinese Journal of Tissue Engineering Research, 25(15): 2385-2393.

Su, M. - Xu, S. - Weng, J. (2021): A Bibliometric Study of COVID-19 Research in Web of Science. Letter to the Editor. Pharmacological Research, 169(105664).

Torres-Salinas, D. - Robinson-Garcia, N. - Castillo-Valdivieso, P. A. (2020): Open Access and Altmetrics in the Pandemic Age Forescast Analysis on COVID-19 Related Literature. BioRxiv, 26: 420.

Van Dalen, H. P. (2001): What Makes a Scientific Article Influential: The Case of Demographers. Scientometric, 50(3): 455-482.

Wagner, C. S. - Park, H. W. - Leydesdorff, L. (2015): The Continuing Growth of Global Cooperation Networks in Research: A Conundrum for National Governments. Plos One, 10(7): e0131816.

Wang, P. - Tian, D. (2021): Bibliometric Analysis of Global Scientific Research on COVID-19. Journal of Biosafety and Biosecurity, 3(1): 4-9.

Webb, A. - McQuaid, R. - Rand, S. (2020): Employment in the Informal Economy: Implications of the COVID-19 Pandemic. International Journal of Sociology and Social Policy, 40(9/10): 1005-1019.

Williams, C. C. - Oz-Yalaman, G. (2021): The Coronavirus Pandemic, Short-Term Employment Support Schemes and Undeclared Work: Some Lessons from Europe. Employee Relations, 43(3): 630-643.

Wuchty, S. - Jones, B. F. - Uzzi, B. (2007): The Increasing Dominance of Teams in Production of Knowledge. Science, 316(5827): 1036-1039. 
Yeo-Teh, N. S. L. - Tang, B. L. (2020): An Alarming Retraction Rate for Scientific Publications on Coronavirus Disease 2019 (Covid-19). Accountability in Research, 28(1): 47-53.

Yu, Y. - Li, Y. - Zhang, Z. - Gu, Z. - Zhong, H. - Zha, Q. - Yang, L. - Zhu, C. - Chen, E. (2020): A Bibliometric Analysis Using VOSviewer of Publications on COVID-19. Annals of Translational Medicine, 8(13): 816.

Zaremba, A. - Kizys, R. - Aharon, D. Y. - Demir, E. (2020): Infected Markets: Novel Coronavirus, Government Interventions, and Stock Return Volatility Around the Globe. Finance Research Letters, 35 (July): 101597.

Zhang, D. Y. - Hu, M. - Ji, Q. (2020b): Financial Markets Under the Global Pandemic of COVID-19. Finance Research Letters, 36(October): 101528.

Zhang, L. - Zhao, W. - Sun, B. - Huang, Y. - Glänzel, W. (2020a): How Scientific Research Reacts to International Public Health Emergencies: A Global Analysis of Response Patterns. Scientometrics, 124(1): 747-773.

Zhang, Y. - Cai, X. - Fry, C. V. - Wu, M. - Wagner, C. S. (2021): Topic Evolution, Disruption and Resilience in Early COVID-19 Research. Scientometrics, 126(3): 4225-4253.

Zyoud, S. H. - Al-Jabi, S. W. (2020): Mapping the Situation of Research on Coronavirus Disease-19 (COVID-19): A Preliminary Bibliometric Analysis During the Early Stage of the Outbreak. BMC Infectious Diseases, 20(1): 561.

\section{APPENDIX}

\begin{tabular}{|l|c|c|c|c|}
\hline \multirow{2}{*}{} & \multicolumn{2}{|c|}{$\begin{array}{c}\text { Institutions by the total } \\
\text { database }\end{array}$} & \multicolumn{2}{c|}{$\begin{array}{c}\text { Institutions by the CEE } \\
\text { database }\end{array}$} \\
\cline { 2 - 5 } & Number & $\%$ & Number & $\%$ \\
\hline Public institutions or non-profit organizations & 344 & 18.8 & 11 & 11.3 \\
\hline Education & 1,377 & 75.2 & 78 & 80.5 \\
\hline Private companies & 99 & 5.4 & 7 & 7.2 \\
\hline N.a. & 12 & 0.6 & 1 & 1.0 \\
\hline Total & 1,832 & 100.0 & 97 & 100.0 \\
\hline
\end{tabular}

Open Access. This is an open-access article distributed under the terms of the Creative Commons Attribution 4.0 International License (https://creativecommons.org/licenses/by/4.0/), which permits unrestricted use, distribution, and reproduction in any medium, provided the original author and source are credited, a link to the CC License is provided, and changes - if any - are indicated. (SID_1) 